\title{
Gas Chromatography-Mass Spectrometer Electron Ionization (GC-MS - EI) method for the Analysis of MalathionResidue in Tomato
}

Abdalla Ahmed Elbashir ${ }^{\star}$,Yasmin Alsadig Mohammed Elnour, Hassan Elobid Ahmed University of Khartoum, Faculty of Science, Chemistry Department, Khartoum, 11115, Sudan, P.O box 321 Authors of correspondence

Dr. AbdallaA.Elbashir, e-mail:hajaae@yahoo.com

\section{ABSTRACT}

In this a study tomato sampleswere collected from Khartoum, extracted with acetone, dichloromethane and petroleum ether $(1: 1: 1)$ and cleaned up by florisil column. Malathion quantitative determination is carried out by gas chromatographmass spectrometerusing the optimum ionization mode electron ionization (EI). The detection ofmalathionis confirmed by retention time and comparison of primary and secondary ions.Recovery studies were performed at two spikes $\left(0.5,0.25 \mathrm{mg} \mathrm{kg}^{-1}\right)$ fortification levels of malathion and the recovery obtained ranged from $81 \%$ to $97 \%$. The method showed good linearity $\left(\mathrm{R}^{2}>0.995\right.$ ) over the range assayed (from 0.05 to $7.0 \mathrm{mg} \mathrm{L}^{-1}$ ) and the calculated limits of detection (LOD) and quantification(LOQ) were $0.03 \mathrm{mg} \mathrm{kg}^{-1}$ and $0.11 \mathrm{mg} \mathrm{kg}^{-1}$, respectively. These limits werelower than the maximum residue levels(MRL) established by European legislations $\left(0.5 \mathrm{mg} \mathrm{kg}^{-1}\right)$.

Keywords: Tomato; Malathion; Gas chromatography-mass spectrometer;Electronimpact ionization;Florisil.

\section{Council for Innovative Research}

Peer Review Research Publishing System

Journal: Journal of Advances in Chemistry

Vol 2, No. 1

editor@cirworld.com

www.cirworld.com, member.cirworld.com 


\section{INTRODUCTION}

During the last two decades there have been growing social concerns over issues related to public health, environmental quality, and food safety. One of the major controversies inciting these concerns involves the production and consumption of fresh fruit and vegetables. Research has shown that diets with greater proportions of fruit and vegetables can prevent or delay a number of life threatening diseases. At the same time, public acceptance and adoption of these findings is being discouraged by ongoing re-evaluations of the possible health risks associated with minute amounts of pesticide residues sometimes found in or on these foods. The application of pesticides is essential in modern agricultural practices to control pest and diseases that damage fruit and vegetables. However, it has the drawback of pesticide residues which remain on fruit and vegetables, constituting a possible risk to consumers. [1] Therefore, governments and international organizations(FAO, WHO) have established maximum residue levels (MRLs), limiting the amount of pesticides in foods. Currently organophosphates, carbamates and pyrethroids are mostly used while someorganochlorine insecticides have been banned because of their toxicity, persistent and bioaccumulation in the environment[2].

A wide variety of techniques have been used to extract and to purify pesticides from fruit and vegetables, including liquidliquid extraction (LLE) [3] solid-phase extraction (SPE) [4] accelerated solvent extraction (ASE) [5], gel permeation chromatography(GPC) [6], and supercritical fluid extraction (SFE)[7].

The most frequently used technique for analysis of pesticide residues in fruit and vegetables is gas chromatography with different selective detectors. Such as flame photometric (FPD) [8], nitrogen-phosphorus (NPD) [9], and electron-capture detectors(ECD) $[10,11]$. Numerous methods use gas chromatography coupled with mass spectrometry (GC-MS) due to the possibility of confirming pesticide identity in these matrices[12,13].Liquid chromatography coupled with tandem mass spectrometry (LC-MS-MS)[14, 15]has lately become a powerful analytical technique for the identification and quantification of residues in fruit and vegetable. A critical review of literature showed that different solvents such as $n$ hexane, petroleum ether,methylene chloride and acetone or ethyl acetate have been used for extraction of pesticide residue from fruit and vegetables [16]. As more polar pesticides, such as organophosphate and phenoxyaceticacid, polar solvents such as chloroform, acetone, acetonitrile and methanol were found to be good[17]. Ethyl acetate isfound to be a good solvent as compared to other solvents forthe extraction of residues of several pesticides from fruit and vegetables because its polarity is high and it is a less volatile and thermally labile compound[18].

Malathionis a broad spectrum, non-systemic Organophosphorous insecticide that is used on a wide variety of crop sites and on various non-crop sites, including greenhouses, nurseries, home and garden, and public health. The chemicalstructure ofmalathion is shown in Figure 1. It is very highly toxic to fish and aquatic invertebrates but does not appear to be toxic to plants. Some residential and agricultural uses can have rather high application rates and resulting exposure.

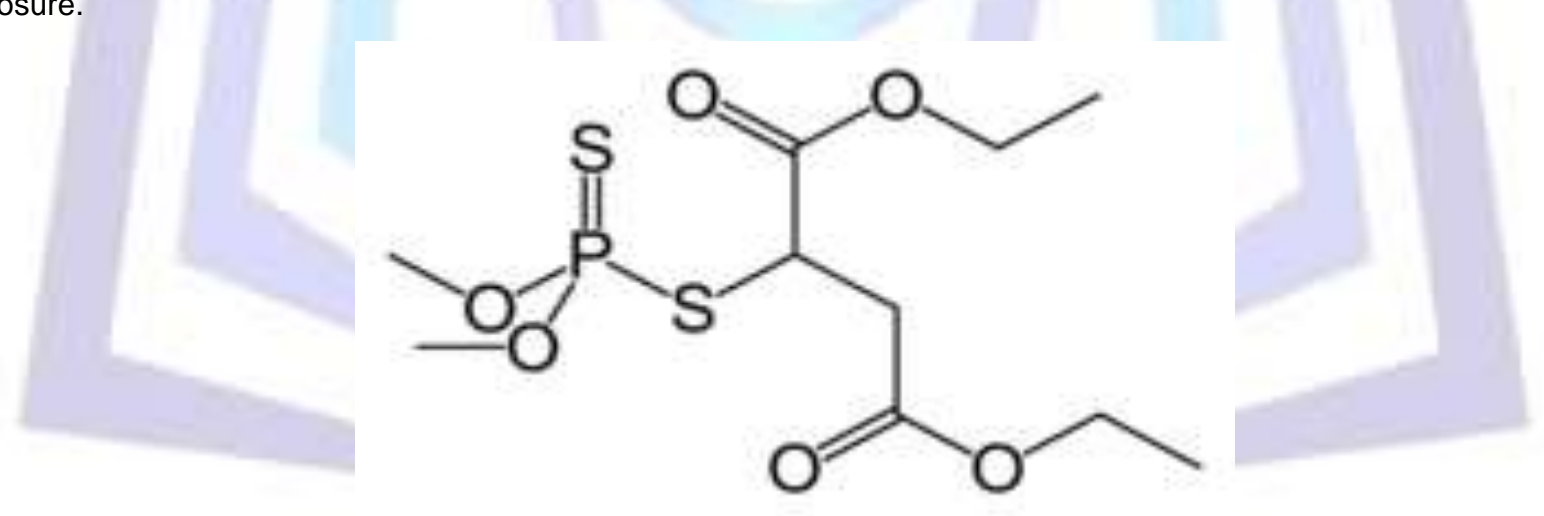

Fig. 1.Malathion or 2-(dimethoxyphosphinothioylthio) butanedioic acid diethyl ester

The present work is designed to study the residues of malathion pesticides in tomato, a sample is extracted with simple and effective procedure using low volume of organic solvent, cleanup is carried by florisil columns and residue levels were determined by gas chromatography (GC) with mass spectrometer detector (GC-MSD.

\section{EXPERIMENTAL}

\section{Reagents and Chemicals}

Acetone, dichloromethane, petroleum ether and n-hexane, of special gradingfor the pesticide residue analysis, were obtained fromScharlau Company.

\section{INSTRUMENTATION}

A Shimadzu GC-2010 gas chromatograph with a QP-2010plus mass spectrometer (Japan) was used. The GC system, with an electronic ionization (EI), was equipped withAOC 500 Auto injector autosampler and a splitless injection port. 
Chromatographic separation was performed on column RTx-5MS (5\% phenyl-95\% polydimethylsiloxane; $30 \mathrm{~m} \times 0.25 \mathrm{~mm}$ ID, $0.25 \mu \mathrm{m})$.

\section{Chromatographic conditions}

Heliumwas used as carrier gas at a constant flow-rate of $0.9 \mathrm{~mL} \mathrm{~min}^{-1}$. The column temperature was programmed as follows: $90^{\circ} \mathrm{C}$ for. $6 \mathrm{~min}, 20^{\circ} \mathrm{C} / \mathrm{min}$ to $200^{\circ} \mathrm{C}\left(6 \mathrm{~min}\right.$.) and $20^{\circ} \mathrm{C} / \mathrm{min}$ to $260^{\circ} \mathrm{C}(5 \mathrm{~min})$. The solvent delay was $2.5 \mathrm{~min}$. The total analysis time was $20 \mathrm{~min}$. The injection port was maintained at $200{ }^{\circ} \mathrm{C}$ and $1 \mu \mathrm{L}$, sample volumes were injected in splitless mode. The data were acquired and processed using Shimadzu GC Solution software. The eluent from the GC column was transferred via a transfer line heated at $280^{\circ} \mathrm{C}$ and fed into a $70 \mathrm{eV}$ electron impact ionization source, also maintained at $280{ }^{\circ} \mathrm{C}$. Table 1 lists the pesticides along with their retention times, molecularmass, the target and qualifier ions, and their qualifierto target abundance ratios. The target abundances were determined by injection of pesticide standards under the same chromatographic conditions using full scan mode with the mass/charge ratio ranging of the $\mathrm{m} / \mathrm{z}$ 10 to 400 . In these evaluations, the characteristic ions were chosen, and the MS system was then programmed in selective ion monitoring (SIM) mode for quantification of pesticide. The choice of the ions for SIM acquisition was based on the best $S / N$ ratioswas $m / z 100,125$ and 127 .Values of $m / z$ in bold type correspond to the quantification ion for analyte.

For the extraction of samples, a Polytron PT2000 homogenizer(Kinematical AG, Lucerne, Switzerland) was used.AnEppendorf model 5810R centrifuges (Hamburg, Germany)and a Bu"chi model R-200rotavapor (Flawil, Switzerland)was used in the centrifugation and evaporationto dryness of samples, respectively.

Table 1: Retention time (RT, min), molecular weight (MW), target (T), qualifier ions (Q1, Q2) (m/z) and abundance ratios (\%) of qualifier ion/target-ion(Q1/T, Q2/T) of the Malathion pesticides.

\begin{tabular}{|c|c|c|c|c|c|c|c|}
\hline Malathion & RT & MW & T & Q1 & Q2 & Q1/T & Q2/T \\
\hline \multirow{5}{*}{} & 12.622 & 330.4 & 127 & 125 & 100 & 44.66 & 25.30 \\
& 12.613 & 330.4 & 127 & 125 & 100 & 46.54 & 25.75 \\
& 12.617 & 330.4 & 127 & 125 & 100 & 49.67 & 29.40 \\
& 12.600 & 330.4 & 127 & 125 & 100 & 46.59 & 24.35 \\
& 12.606 & 330.4 & 127 & 125 & 100 & 46.16 & 23.47 \\
& 12.611 & 330.4 & 127 & 125 & 100 & 46.21 & 23.17 \\
& 12.614 & 330.4 & 127 & 125 & 100 & 43.26 & 30.20 \\
& 12.619 & 330.4 & 127 & 125 & 100 & 55.17 & 18.96 \\
& 12.620 & 330.4 & 127 & 125 & 100 & 59.63 & 15.36 \\
\hline
\end{tabular}

\section{Stock and Standard Solutions}

Pesticides stock solutions $\left(1381 \mathrm{mg} \mathrm{L}^{-1}\right)$ of malathionpesticide standard was prepared by dissolving $0.1381 \mathrm{~g}$ ofthe pesticide in $100 \mathrm{~mL}$ of petroleum ether.A pesticide intermediate standard solution $\left(13.81 \mathrm{mg} \mathrm{L}^{-1}\right)$ was prepared by transferring $1 \mathrm{~mL}$ from pesticide solutionto a $100 \mathrm{ml}$ volumetric flask and diluting to volumewith petroleum ether to obtain a concentrationof13.81 $\mathrm{mg} \mathrm{L}^{-1}$. Several standardsolutions, withconcentrationsof $\left(0.05-7.0 \mathrm{mg} \mathrm{L}^{-1}\right)$, wereinjectedtoobtainthe linearity of detector response and the detection limitsof the pesticides studied.

\section{Sample preparation}

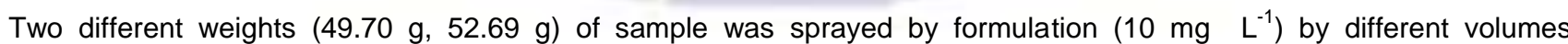
$(1.25 \mathrm{~mL}, 2.5 \mathrm{~mL})$, respectively, then was left until they were dry, extracted, cleaned up and determined .Real sample was carried out by taking sample without spraying and then was extracted, cleaned up and determined.

\section{Extraction}

Each sprayed sample was cut and putin blender and homogenized for $(30 \mathrm{sec})$ with $30 \mathrm{~mL}$ of acetone,60 mL of dichloromethane and petroleumether (1:1) were added and the mixture was homogenized for $(1 \mathrm{~min})$ then centrifuged at $4000 \mathrm{rpm}$ for $(5 \mathrm{~min})$, the volume of extract was concentrated in rotary evaporator with water bath at $35^{\circ} \mathrm{C}$ and then was cleaned up by florisil column and determined $\left.{ }^{[} 19\right]$.

\section{Cleaned up}

All samples were cleaned up by florisil column before analysis by GC-MS. Florisil $(20 \mathrm{~g})$ in hexane was allowed to settle in a chromatographic column $(45 \mathrm{~cm} \times 20 \mathrm{~mm})$ by tapping the column. To the tap of florisil, a layer of 1 to $2 \mathrm{~cm}$ deep anhydrous sodiumsulphate was added. Then the column was eluted with $200 \mathrm{~mL}$ of hexane and the liquid was discarded. Concentrated sample of tomato extract $(1 \mathrm{~mL})$ in hexane was transferred to the column,and then the column was eluted 
with 200 mLof $15 \%$ diethyl ether in hexane followed by $200 \mathrm{~mL}$ of $50 \%$ diethyl ether in hexane. The solution was evaporated to $5 \mathrm{~mL}$ and injected in GC-MS.

\section{RESULTS AND DISCUSSION}

\section{Gas chromatographic determination}

Pesticides residue levels were determined by GC-MS. Representative mass spectrum andchromatograms of a standard pesticideare shown in(Figure 2 (a), (b), and that for a tomato sample spiked with the formulation of the malathionsolution and real sample are shownin( Figure 3 (a), (b), respectively.
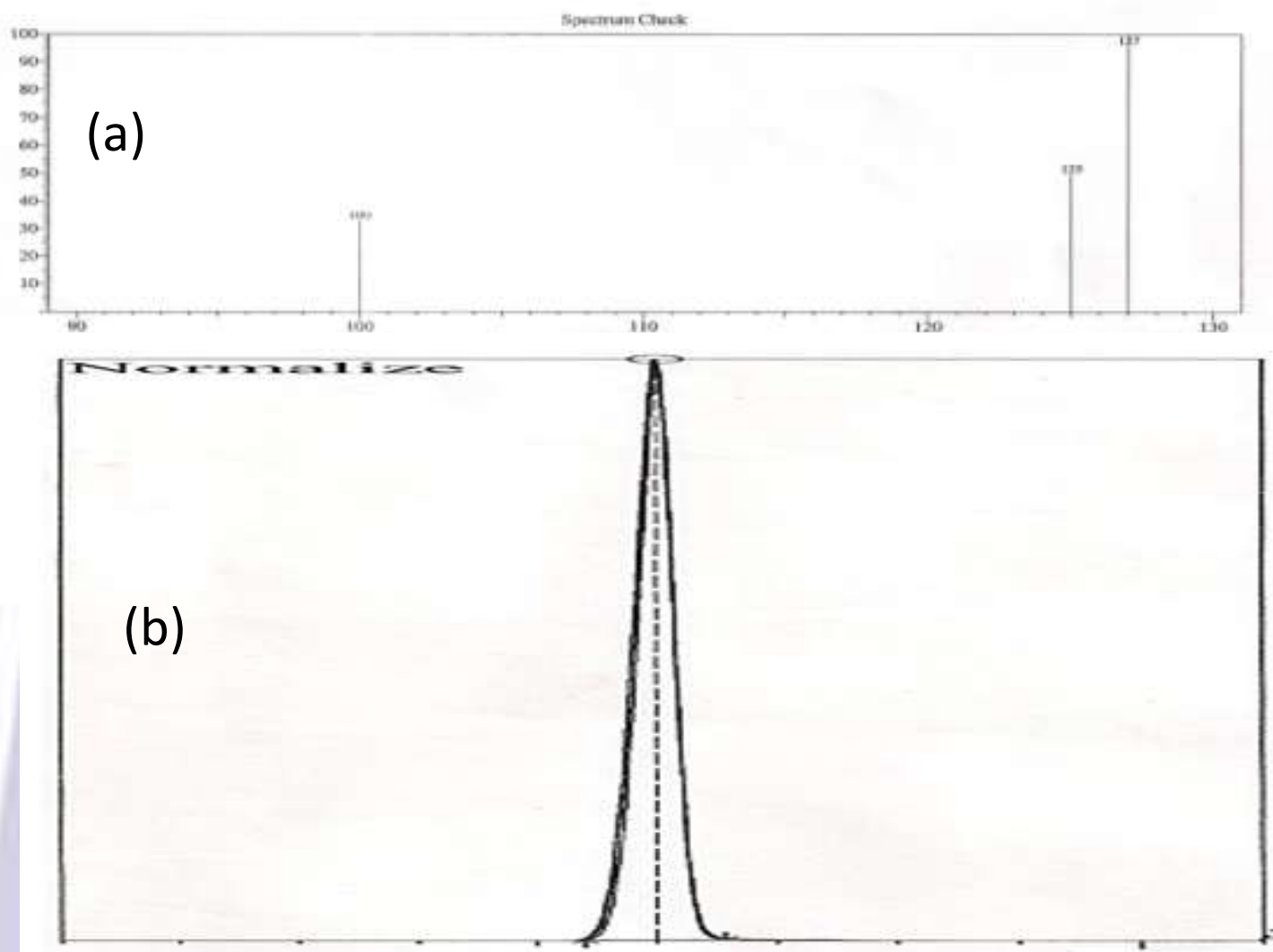

Fig. 2. (a)Mass spectrum (GC-MS-EI) of malathion fragment, (b) Chromatogram (GC-MS-EI) of standardmalathion.
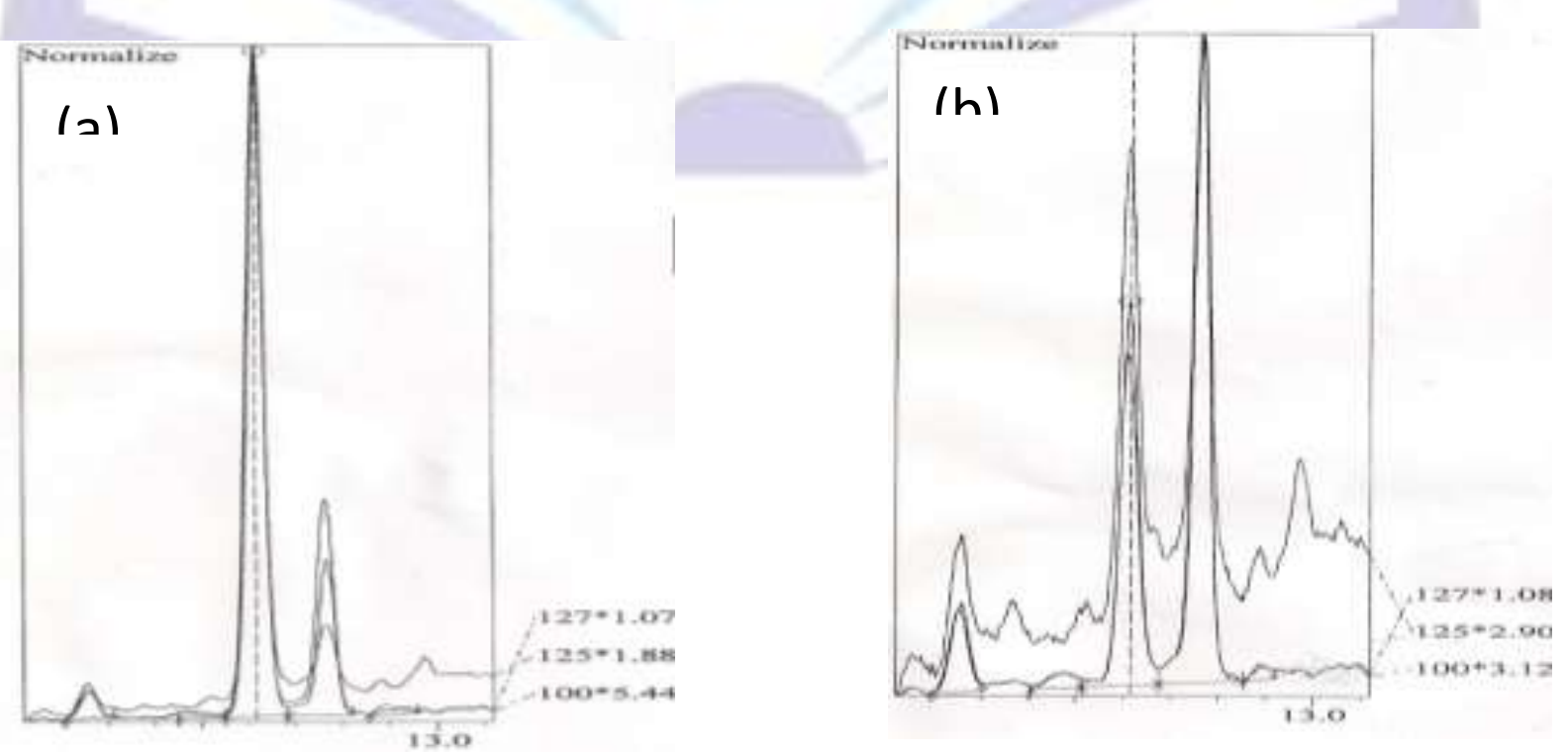

Fig 3 (a) Chromatograms (GC-MS-EI) obtained for (a) (spicke $0.25 \mathrm{mg} \mathrm{kg}^{-1}$ ) (b) Areal tomato sample. 


\section{Method validation}

The MS response for pesticides was linear in the concentration assayed $\left(0.05-7.0 \mathrm{mg} \mathrm{L}^{-1}\right)$ with determination coefficients $>0.995$ for pesticides. The results are shown inTable 2 .

Table 2: Calibration range $\left(0.05-7 \mathrm{mg} \mathrm{L}^{-1}\right)$

\begin{tabular}{|c|c|c|}
\hline Number & Conc. $\left(\mathrm{mg} \mathrm{L}^{-1}\right)$ & Mean Area \\
\hline 1 & 0.05 & 834 \\
2 & 0.1 & 1718 \\
3 & 0.5 & 3051 \\
4 & 3 & 812336 \\
5 & 5 & 1362964 \\
6 & 7 & 1721302 \\
\hline
\end{tabular}

\section{Limit of Detection and Quantitation}

The limit ofdetection (LOD) of the method was determined at a signal-to-signal ratio of 3 for the pesticides in tomato by GC-MS, whereas the limit of quantification was obtained at a signal-to-signal ratio of 10 .The LOD is $0.03 \mathrm{mg} \mathrm{kg}^{-1}$ and the LOQ is $0.11 \mathrm{mg} \mathrm{kg}^{-1}$.

\section{Recovery}

A study of recoveries for pesticide at two different fortification levels was carried out in order to assess the extraction efficiency of the method. For that, two tomato samples were spikedwith $\left(0.5,0.25 \mathrm{mg} \mathrm{kg}^{-1}\right)$ of pesticide and processedas described. A recovery data obtained are shown in Table 3.

Table 3: Recovery of pesticides from spiked Tomato samples

\begin{tabular}{|c|c|c|}
\hline Pesticide & Fortificationlevel $\left(\mathrm{mg} \mathrm{kg}^{-1}\right)$ & recovery \\
\hline Malathion & & $81 \%$ \\
& 0.5 & $97 \%$ \\
\hline
\end{tabular}

\section{Analysis of real samples}

Tomato samples were analyzed following the extraction methods described above. Pesticide concentration levels in the real samplewere found to be $0.3 \mathrm{mg} \mathrm{kg}^{-1}$. Analysis of samples showed the validity of method used, which allowed the determination and identificationof pesticides present in the samples.

\section{CONCLUSION}

The results of this study show that the method to determine residues of pesticides in tomatois rapid, simple, sensitive and uses small volumesof solvents for sample extraction, reducing the risk for human health andthe environment.Good recovery and low detection throughmethod were obtained for the pesticides studied,including new generations of pesticides, since their decompositions quicker and has a less damaging effect on theenvironment. The method shows advantages comparedwith other conventional methods in that, the use of a lowvolume of organic solvent in the sample extraction, it avoids the use of a chlorinated hydrocarbon, and the time of extraction is short.

\section{REFERENCES}

[1] Fenoll, J., Hellín, P., Martínez, C.M., Miguel, M., Flores, P.Multiresidue method for analysis of pesticides in pepper and tomato by gas chromatography with nitrogen-phosphorus detection.J. Food Chem. 2007,105,711-719.

[2] Islam, S., Hossain, M.S., Nahar, N., Mosihuzzaman, M., Mamun, M.I.R.Application of high performance liquid chromatography to the analysis of pesticide residues in eggplants $\mathrm{J}$ of Appl Sci. 2009,9,973-977.

[3] Luke, M.A., Froberg, J.E., Masumoto, H.T.Extraction and cleanup of organochlorine, organophosphate, organonitrogen, and hydrocarbon pesticides in produce for determination by gas-liquid chromatography.J. AOAC.1975, $58,1020-1026$. 
[4] Rotich, H.K., Zhang, Z., Li, J.Optimization of high-performance liquid chromatography and solid-phase extraction for determination of organophosphorus pesticide residues in environmental samples. J. Inter Env.Anal. Chem. 2003,83,851860.

[5] Adou, K., Bontoyan, W.R., Sweeney, P.J.Multiresidue method for the analysis of pesticide residues in fruits and vegetables by accelerated solvent extraction and capillary gas chromatographyJ. Agric and Food Chem. 2001,49,41534160.

[6] Stan, H. J. Pesticide residue analysis in foodstuffs applying capillary gas chromatography with mass spectrometric detection - State-of-the-art use of modified DFG-multimethod S19 and automated data evaluationJ. Chrom A. 2000,892,347-377.

[7] Valverde-García, A., Fernandez-Alba, A.R., Contreras, M., Agu $\square$ era, A.Supercritical fluid extraction of pesticides from vegetables using anhydrous magnesium sulfate for sample preparation. J. Agric and Food Chem. 1996,44,1780-1784.

[8] Ueno, E., Oshima, H., Saito, I., Matsumoto, H., Nakazawa, H.Multiresidue analysis of pesticides in agricultural products by GC-ECD after GPC and graphitized carbon column cleanup J. Food HygSoc Japan. 2004,45,212-217.

[9] Ueno, E., Oshima, H., Saito, I., Matsumoto, H.Multiresidue analysis of organophosphorus pesticides in vegetables and fruits using dual-column GC-FPD, -NPD. J. Food HygSoc Japan. 2001,42:385-393.

[10] Gelsomino, A., Petrovičová, B., Tiburtini, S., Magnani, E., Felici, M.Multiresidue analysis of pesticides in fruits and vegetables by gel permeation chromatography followed by a gas chromatography with electron-capture and mass spectrometric detectionJ. ChromA. 1997,782,105-122.

[11] Abuzar E. A. E. Albadri, Abdalla A. Elbashir, Hassan El-obid Ahmed, Ibrahim A. M. Mihaina\& Hassan Y. Aboul-Enein A Gas Chromatographic Method with Electron-Capture Detector (GC-ECD) for Simultaneous Determination of Fenpropathrin, I-Cyhalothrin, and Deltamethrin Residues in Tomato and Its Applications to Kinetic Studies After Field Treatment

[12] Gamón, M., Lleó, C., Ten, A., Mocholí, F.Multiresidue determination of pesticides in fruit and vegetables by gas chromatography/tandem mass spectrometryJ. AOAC. 2001, 84,1209-1216.

[13] Akiyama, Y., Yano, M., Mitsuhashi, T., Takeda, N., Tsuji, M.Simultaneous determination of pesticides in agricultural products by solid-phase extraction and gas chromatography-mass spectrometry. J. Food Hygienic Society of Japan, 1996, $37,351-362$

[14] Choi, B.K., Hercules, D.M., Gusev, A.I.LC-MS/MS signal suppression effects in the analysis of pesticides in complex environmental matrices. Fresenius' J. Anal.Chem.2001,369, 370-377.

[15] Mol, H.G.J., Van Dam, R.C.J., Steijger, O.M.Determination of polar organophosphorus pesticides in vegetables and fruits using liquid chromatography with tandem mass spectrometry: Selection of extraction solvent . J. Chrom A. 2003,1015,119-127.

[16] Kearney and P. Philip, 1978.Advances in pesticide science.Proceedings of the 4th International Congress of Pesticide Chemistry. Zurich, Switzerland. Jul. 24-28, Elsevier Science and Technology Books.

[17] Luke, M.A., Froberg, J.E., Doose, G.M., Masumoto, H.T.Improved multiresidue gas chromatographic determination of organophosphorus, organonitrogen, and organohalogen pesticides in produce, using flame photometric and electrolytic conductivity detectors. J.AOAC. 1981,64,1187-1195.

[18] Startin, J.R., Sykes, M.D., Taylor, J.C., Hird, S.J., Jackson, K., Fussell, R.J., Hill, A.R.C.Determination of residues of pirimicarb and its desmethyl and desmethylformamido metabolites in fruits and vegetables by liquid chromatographyelectrospray/mass spectrometry,J. AOAC,2000,83,735-741.

[19] Anderson, A. and H. Palsheden, 1998.Uppsala, Sweden:Nat.Food Administ.Rapport.17: 9-1. 


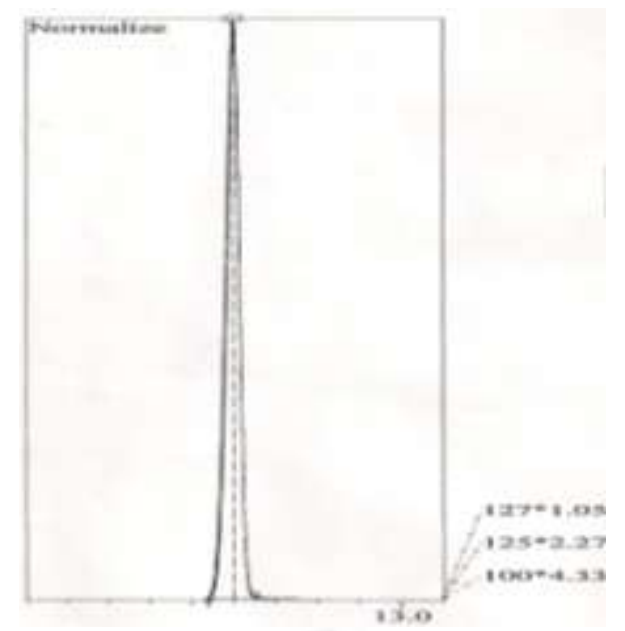

Fig. 2b: Chromatogram (GC-MS-EI) obtained for: standard malathion

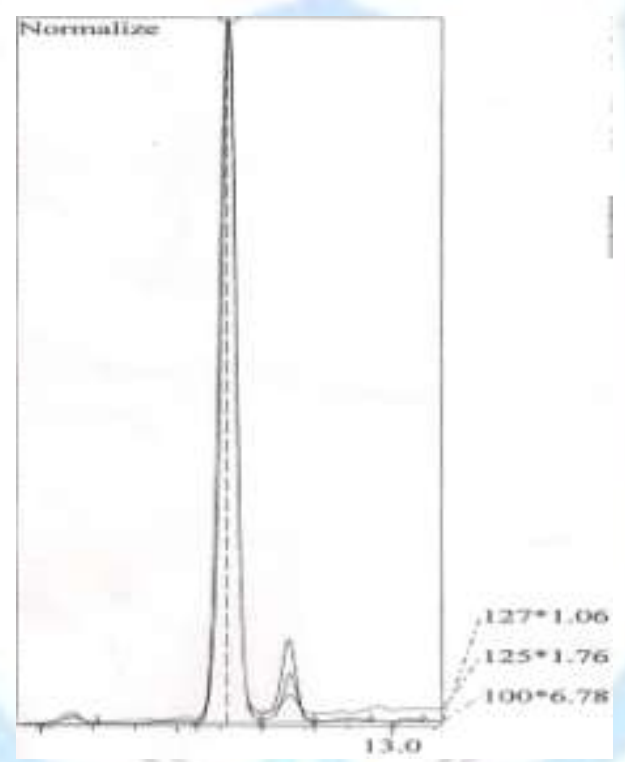

Fig 3a: Chromatograms (GC-MS-EI) obtained for: (spicke $0.5 \mathrm{mg} \mathrm{kg}^{-1}$ ) 


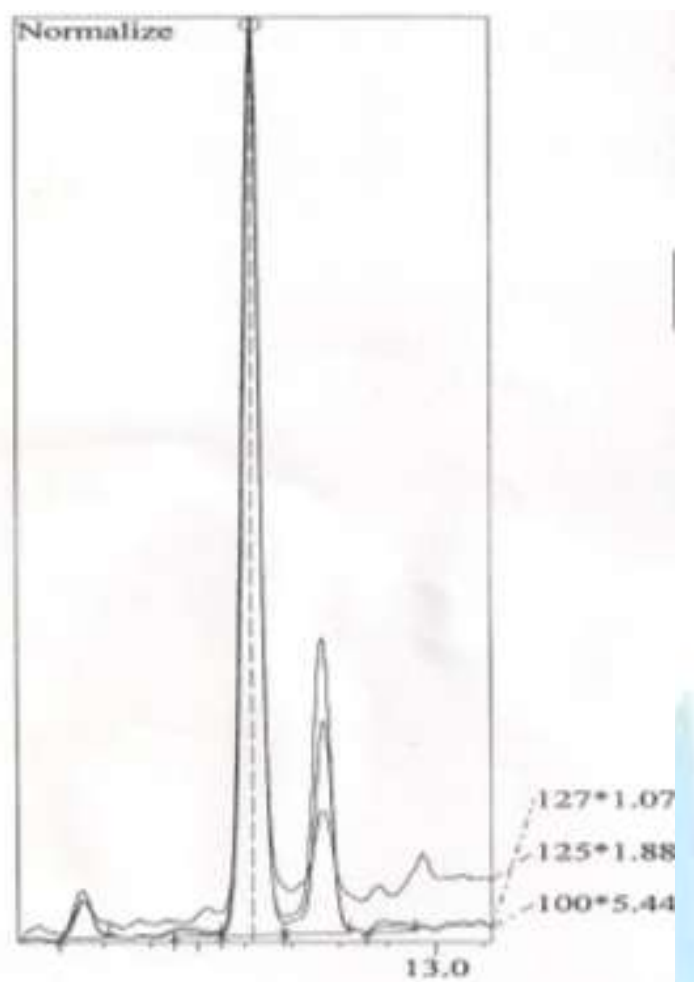

Fig 3b: Chromatograms (GC-MS-EI) obtained for: (spicke0.25 mg kg ${ }^{-1}$ ). 


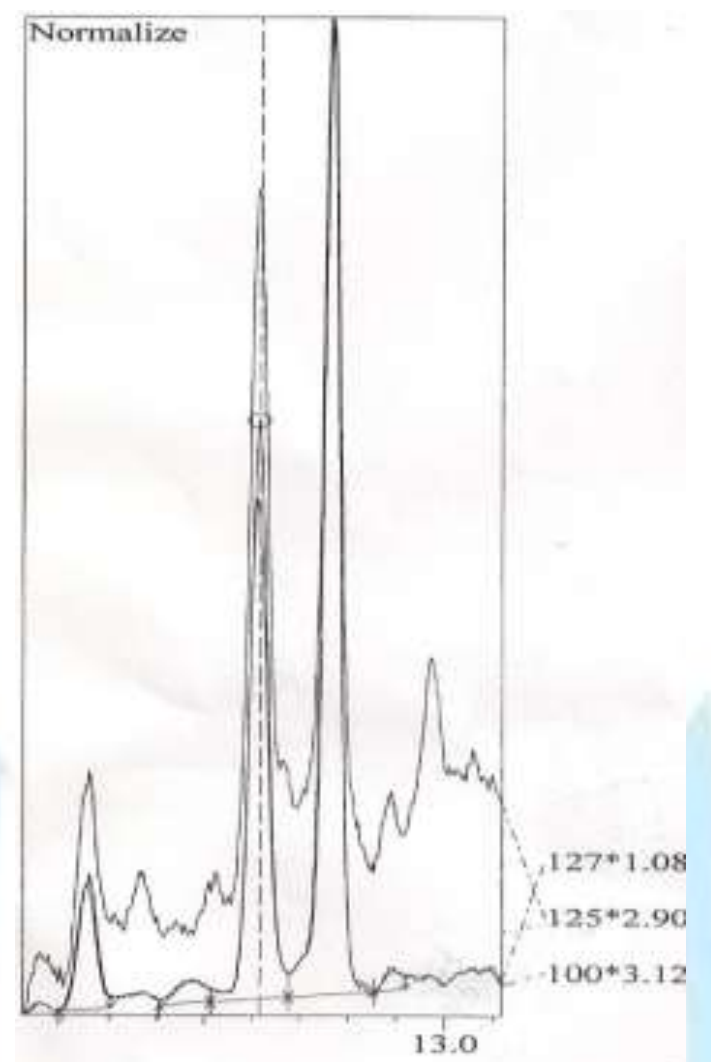

Fig 3c: Chromatograms (GC-MS-EI) obtained for: Areal tomato sample.

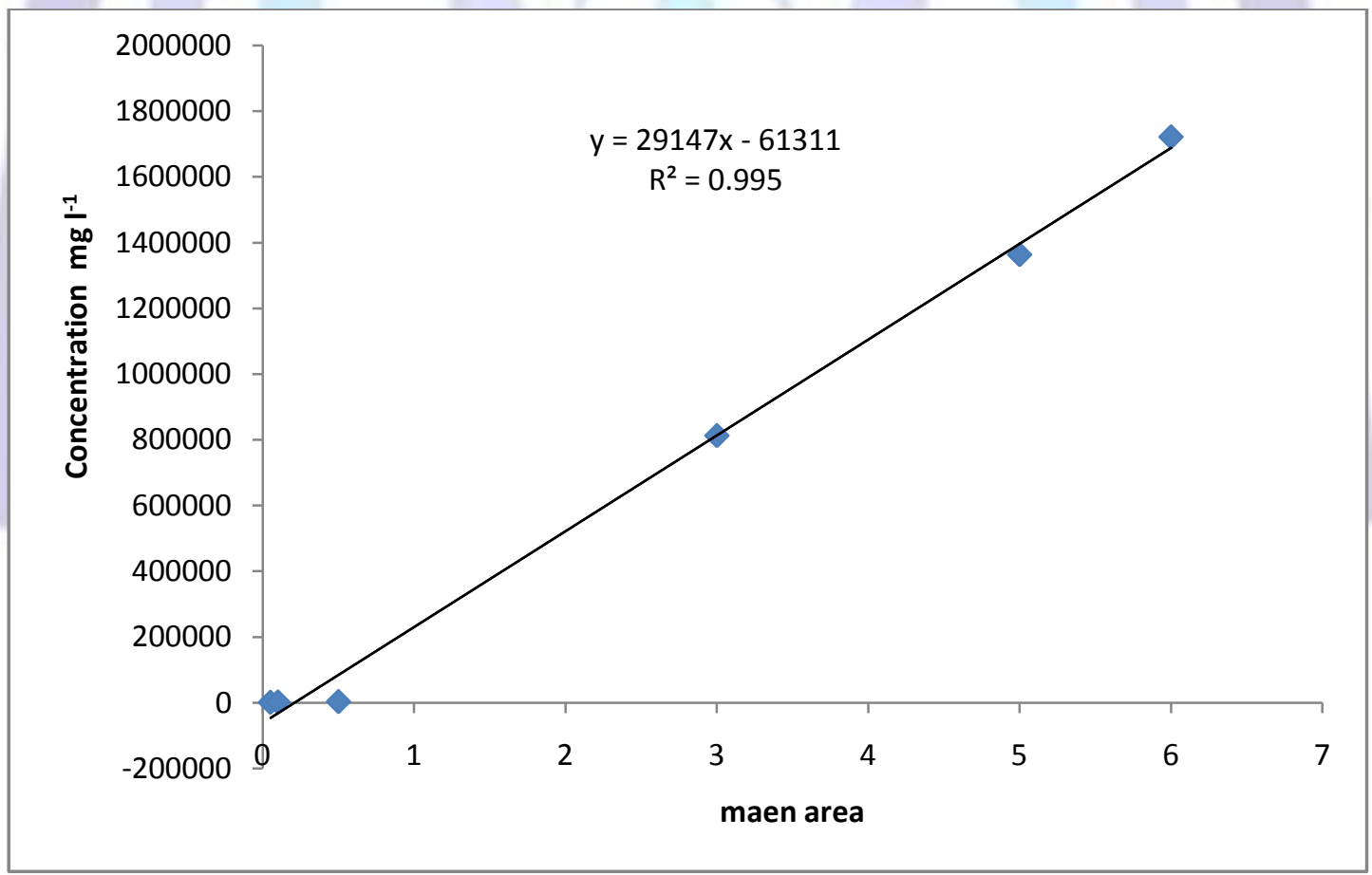

Fig.4: Calibration curve ofmalathion standard. 